\title{
Longitudinal assessment of the effects of estrogen on blood pressure and cardiovascular autonomic activity in female rats
}

\author{
Mahmoud M. El-Mas and Abdel A. Abdel-Rahman \\ Department of Pharmacology, School of Medicine, East Carolina University, Greenville, North \\ Carolina, U.S.A.
}

\begin{abstract}
1. Published data concerning the effect of ovarian hormones on hemodynamic variability is contradictory. This study employed, for the first time, radiotelemetric hemodynamic monitoring to investigate the long-term effects of chronic estrogen depletion and repletion on cardiovascular autonomic control and arterial baroreflex sensitivity (BRS) in female rats.

2. Blood pressure (BP), heart rate (HR), and $+\mathrm{dP}^{\mathrm{dt}} \mathrm{tmax}_{\max }$ of arterial pressure (an estimate of myocardial contractility) were monitored in sham-operated (SO), ovariectomized (OVX), and estrogen-replaced OVX rats $\left(\mathrm{OVXE}_{2}\right)$ for 16 weeks. Cardiovascular autonomic control and baroreflexes were assessed by frequency domain analysis of interbeat intervals (IBI) and systolic $\mathrm{BP}$ (SBP).

3. Compared with SO rats, OVX rats exhibited (i) no changes in BP, (ii) short-lived decreases in $\mathrm{HR}$, and (iii) sustained reductions in $\mathrm{dP} / \mathrm{dt}_{\max }$ of arterial pressure. The high frequency (HF, 0.75-3 $\mathrm{Hz}$ ) and low frequency (LF, $0.25-0.75 \mathrm{~Hz}$ ) components of spectral power of IBI were significantly decreased and increased, respectively, by ovariectomy. An increase in the $\mathrm{IBI}_{\mathrm{LF} / \mathrm{HF}}$ ratio in $\mathrm{OVX}$ rats suggested a shift in the cardiac sympathovagal balance towards sympathetic dominance. Index $a$, the spectral index of spontaneous BRS, was reduced by OVX.

4. Estrogen replacement caused significant reductions in BP and HR and reversed OVX-induced changes in $+\mathrm{dP}^{-\mathrm{dt}_{\max }}$ of arterial pressure and cardiac autonomic activity. The LF oscillations of $\mathrm{SBP}$ were reduced in $\mathrm{OVX}-\mathrm{E}_{2}$ treated rats, suggesting a reduction in vascular sympathetic tone by estrogen.
\end{abstract}

5. These findings highlight the importance of long-term estrogen therapy in rectifying the detrimental cardiovascular and baroreflex influences caused by depletion of ovarian hormones.

\section{Keywords}

Blood pressure; estrogen; female rats; frequency spectral analysis; hemodynamic variability; myocardial contractility; ovariectomy; radiotelemetry; spontaneous baroreflex sensitivity
Epidemiological studies have shown that the incidence of cardiovascular disease is relatively low among premenopausal women and exhibits a sharp rise with the occurrence of menopause (1). The increased risk of heart disease in young women with bilateral oophorectomy (2) and the beneficial effect of estrogen replacement therapy in postmenopausal women (3) further support a cardiovascular protective role for estrogen.

\footnotetext{
Author for correspondence: Abdel A. Abdel-Rahman, Ph.D., Department of Pharmacology, School of Medicine, East Carolina University, Greenville, NC 27834. Tel. (252)744-3470; Fax (252)744-3203; abdelrahmana@ecu.edu.

Dr. M. M. El-Mas is on a sabbatical leave from the department of Pharmacology, Faculty of Pharmacy, University of Alexandria, Egypt (mahelm@hotmail.com).
} 
Several mechanisms have been suggested to explain the favorable cardiovascular effects of estrogen. Estrogen has a beneficial effect on plasma lipoprotein, decreasing LDL cholesterol and increasing HDL cholesterol (4). Further, estrogen facilitates vasodilation by stimulating prostacyclin and nitric oxide synthesis as well as by decreasing the production of vasoconstrictor substances, such as cyclooxygenase-derived products, reactive oxygen species, angiotensin II, and endothelin-1 (5). The generally accepted cardioprotective role for estrogen (1-4) had been challenged by findings from the Women's Health Initiative study (WHI), which showed that estrogen given alone or combined with progesterone paradoxically increases the risk of heart attacks and stroke in postmenopausal women $(6,7)$. It is notable, however, that re-examination of the results of the WHI study $(8,9)$ has identified important limitations and confounding factors such as: (i) the use of relatively high doses of conjugated equine estrogens by the WHI subjects, (ii) the study subjects were women who started estrogen replacement therapy at least 10 years after entering menopause, and (iii) some flaws in statistical analysis and data interpretations.

The role of defective cardiovascular autonomic regulation in cardiac morbidity and mortality has been established. Decreased heart rate variability (HRV) is closely linked to potentially serious cardiovascular events and predicts overall mortality in the general population $(3,10)$. Therefore, estrogen might confer cardiovascular benefits via modulation of the autonomic control of HRV and reflexes, which have been widely used as indirect measures of cardiac sympathovagal balance. In support of this view are the observations: (i) reported studies from our laboratory and others highlight a facilitatory effect for estrogen on cardiac baroreflex responsiveness (11-13) and HRV (14), and (ii) premenopausal women have higher HRV compared with middle-aged men (15) and postmenopausal women (16). These findings highlight a role for gonadal hormones in the age- and sex-related differences in HRV. The favorable autonomic response to estrogen has been attributed to the ability of estrogen to reduce cardiac sympathetic activity (14). Others reported opposite changes in cardiac sympathetic (decreased) and parasympathetic (increased) activities in postmenopausal women receiving estrogen therapy (17). It should be mentioned, however, that the favorable cardiac effects of hormone replacement therapy have been challenged. Contradictory reports showing no effect for estrogen on HRV (18) or even worsened HRV profile after hormone therapy (19) are also available. The discrepancy in the effect of hormonal therapy on HRV may relate to differences in the hormonal preparations and in the dosage and route of administration.

The main objective of the current study was to re-evaluate the long-term effects of bilateral ovariectomy and estrogen replacement on cardiovascular variability and BRS. To our knowledge, this is the first study to employ radiotelemetry for the assessment of the impact of long-term hormonal changes on cardiovascular autonomic control in female rats. The radiotelemetry technique offers the tremendous advantage of precise and continuous hemodynamic measurements under minimal stressful conditions $(20,21)$. Changes in BP, $\mathrm{HR}, \mathrm{dP} / \mathrm{dt}_{\max }$ of arterial pressure, and spectral indices of HRV and BRS were monitored for 16 weeks. As described in previous studies including ours $(17,21,22)$, cardiovascular variability can be categorized into low (IBI-LF; $0.25-0.75 \mathrm{~Hz}$ ) and high (IBI-HF; $0.75-3 \mathrm{~Hz}$ ) frequency powers according to its oscillating frequency. Whereas the LF band represents the sympathetic drive of the heart, the HF component corresponds to respiratory sinus arrhythmia and reflects the cardiac vagal control (23). The ratio of $\mathrm{LF}$ to $\mathrm{HF}\left(\mathrm{IBI}_{\mathrm{LF} / \mathrm{HF}}\right)$ is a measure of the sympathovagal balance of the heart $(21,23)$.

\section{Materials and Methods}

Female Sprague-Dawley rats (9-10 weeks; 190-225 g; Harlan, Indianapolis, IN) were used in the present study. Upon arrival, rats were housed individually in standard plastic cages 
and allowed free access to water and Purina chow and were maintained on a 12-12-h lightdark cycle with light off at 4:00 p.m. Room temperature was maintained at $22 \pm 1^{\circ} \mathrm{C}$. After 1 week acclimatization, rats were fed a standard Lieber-DiCarli high protein liquid diet (Dyets Inc., Bethlehem, PA) for another week before implantation of the telemetry device. Rats received the diet daily $30 \mathrm{~min}$ before the start of the dark cycle. All experiments were approved by the institutional animal care and use committee and carried out in accordance with the Declaration of Helsinki and with the Guide for the Care and Use of Laboratory Animals as adopted and promulgated by the U.S. National Institutes of Health.

\section{Telemetry transmitter implantation}

The description of the telemetry system (Data Sciences Int., St. Paul, MN) and the method used for the telemetry transmitter implantation are detailed in our previous studies $(20,21,24)$. Briefly, rats were anesthetized with i.p injection of a mixture of ketamine (90 $\mathrm{mg} / \mathrm{kg}$; Ketaject) and xylazine (10 mg/kg; Xyla-ject). The abdomen was opened with a midline incision $(4 \mathrm{~cm})$. Another incision $(1.5 \mathrm{~cm})$ was made along the inner thigh to expose the femoral artery. The abdominal wall was pierced with a large bore syringe needle (15 gauge) from the femoral side into the peritoneal cavity. The implant body was placed in the peritoneal cavity and the catheter $(15 \mathrm{~cm})$ was passed caudally through the syringe needle into the thigh area. A 5-cm portion of the catheter was inserted into the femoral artery and secured in place with sutures. Each rat received a subcutaneous injection of the analgesic ketorolac tromethamine ( $2 \mathrm{mg} / \mathrm{kg}$; Toradol) and an intramuscular injection of $60,000 \mathrm{U}$ of penicillin $\mathrm{G}$ benzathine and penicillin $\mathrm{G}$ procaine in an aqueous suspension (Durapen).

\section{Ovariectomy}

Bilateral ovariectomy was performed at the same time of telemetry transmitter implantation as in our previous studies $(20,24)$. The ovaries were isolated, tied off with sterile suture and removed. Sham operation was performed by exposing the ovaries without isolation.

\section{Measurement of plasma estrogen}

Plasma estrogen levels were measured by the radioimmunoassay (Diagnostic Systems Laboratories, Inc., Webster, TX) as described in our previous studies $(20,24)$.

\section{Protocols and experimental groups}

Three groups of rats (sham-operated, OVX, and $\mathrm{OVXE}_{2} ; \mathrm{n}=6-7$ each) matched for body weight were used in the present study. For estrogen replacement, subcutaneous silicone tubing $\left(10 \mathrm{~mm}\right.$ length, $1.57 \mathrm{~mm}$ inner diameter $\times 3.18 \mathrm{~mm}$ outer diameter, Silastic ${ }^{\circledR}$, Dow Corning) filled with approximately $25 \mathrm{mg}$ of $17 \beta$-estradiol-3-benzoate [1,3,5(10)estratriene-3,17 $\beta$-diol-3-benzoate, Sigma] were used as described elsewhere (25). Silastic tubings were sealed with medical adhesive type A (Silastic ®, Dow Corning), gas sterilized, and implanted subcutaneously at the back of the neck in rats anesthetized with isoflurane. The other 2 groups of rats (sham and OVX) received empty silicone tubings. Silastic tubings were implanted 3 weeks after transmitter implantation and OVX/sham operation. Rats in the 3 groups were pair-fed to allow similar nutrient and fluid consumption as in previous studies $(20,24)$. Fresh diets were prepared every other day and stored in the refrigerator until dispensed. Rats were maintained on liquid diet for 16 weeks.

For the determination of plasma estrogen, blood samples were withdrawn from the tail vein of all rats at week 0 (i.e. before OVX or sham operation) and then every other week after the implantation of the $17 \beta$-estradiol-filled or empty Silastic tubings. The collected blood was centrifuged at $5000 \mathrm{rpm}$ for $5 \mathrm{~min}$ and plasma was aspirated and stored at $-80^{\circ} \mathrm{C}$ till analyzed. 


\section{Telemetry data acquisition and analysis}

Individual rat cages were placed on the top of the radio receivers and data were collected using a computerized data acquisition system (Dataquest A.R.T. 4.0, Data Sciences Int.). Hemodynamic measurements (MAP and HR) started immediately after transmitter implantation to ensure proper operation of the system. BP waveforms were sampled at a rate of $1000 \mathrm{~Hz}$ for $20 \mathrm{sec}$ every $10 \mathrm{~min}$. IBI was calculated from BP waveforms. The maximum rate of rise of BP waves was computed by Data Sciences software and served as an estimate of left ventricular contractility $\left(\mathrm{dP} / \mathrm{dt}_{\max }\right)(21,22)$. All parameters were averaged over a 7 day period for weekly values as in our previous studies $(20,24)$.

\section{Spectral analysis of hemodynamic variability}

Spectral hemodynamic fluctuations, quantitative indices of cardiovascular autonomic control (21-23), were used to reflect changes in sympathetic and vagal outflows. Hemodynamic variability was assessed by the frequency domain analysis of systolic blood pressure (SBP) and interbeat interval (IBI) data series as in our previous studies $(21,22)$. Data Sciences software (Dataquest A.R.T. 4.0) uses the periodogram function of the rectangular window for direct transformation of data points into power spectral density graphs. Data were interpolated to obtain equally spaced samples with an effective sampling frequency of $10 \mathrm{~Hz}$ $(0.1 \mathrm{sec})$. A second-order quadratic was employed to fit a smooth curve to the existing data points and produce a smoother visual representation of data. Spectra were integrated into 2 specific frequency bands, $\mathrm{LF}(0.25-0.75 \mathrm{~Hz})$ and $\mathrm{HF}(0.75-3 \mathrm{~Hz})$ bands and expressed in normalized units $\left(\mathrm{LF}_{\mathrm{nu}}\right.$ and $\left.\mathrm{HF}_{\mathrm{nu}}\right)$, which represent the relative value of each power component in proportion to the total power. The representation of LF and HF in mormalized units minimizes the effect of the changes in total power on the values of LF and HF components and emphasizes the balanced behavior of the two divisions of the autonomic nervous system (23). The index a, square roots of the ratio of IBI and SBP powers, at LF $(\mathrm{LFa})$ and $\mathrm{HF}(\mathrm{HFa})$ were computed to reflect changes in spontaneous BRS as in our previous studies. Parameters of hemodynamic variability were averaged over a 7-day period for weekly values.

\section{Drugs}

Ketaject (ketamine), Xyla-ject (xylazine) (Phoenix Pharmaceuticals Inc., St Joseph, MI), Toradol (ketorolac tromethamine, Abbott Labs, Chicago, IL), Durapen (Penicillin G benzathine and penicillin G procaine, Vedco Inc., Overland Park, KS), and 17 $\beta$-estradiol-3benzoate (Sigma Chemical Co., St. Louis, MO) were purchased from commercial vendors.

\section{Statistical analysis}

Data are expressed as means \pm S.E.M. All parameters were averaged over a 7-day period for weekly values. The repeated measures analysis of variance (ANOVA) followed by a Newman-Keuls post-hoc test was used to test for statistical significance. Probability levels less than 0.05 were considered significant.

\section{Results}

The baseline body weights immediately prior to sham operation or OVX were similar in all rat groups (week 0 , Fig. 1). Subsequently, the gain in body weight was significantly greater in OVX rats compared to the other two groups (Fig. 1). Rats in the 3 groups consumed similar amounts of liquid diet ( $\sim 50 \mathrm{ml} /$ day). The plasma estrogen level measured at week 0 (i.e. before OVX or sham operation) was similar in all rat groups (Table 1). Plasma estrogen was dramatically reduced in OVX rats and restored to above-SO levels in estrogen treated OVX rats (Table 1). The highest plasma estrogen level $(253.1 \pm 24.4 \mathrm{pg} / \mathrm{ml})$ was detected in 
OVX-E $E_{2}$ rats 2 weeks after estrogen replacement (i.e. at week 5 of the study) and then the level of estrogen tapered off during subsequent weeks (Table 1).

\section{Hemodynamic and autonomic effects of estrogen depletion and repletion}

The baseline values of MAP, $\mathrm{HR}, \mathrm{dP} / \mathrm{dt}_{\max }$, and spectral measures of cardiovascular autonomic control were similar in SO, OVX and OVX-E 2 rats (Table 2). Hemodynamic changes caused by OVX or estrogen replacement are shown in figures 2 and 3 . With the exception of short-lived increases (week 4; Fig. 2A) and decreases (weeks 4 and 5; Fig. 2B) in MAP and HR, respectively, both hemodynamic variables remained unchanged in OVX compared with SO rat values throughout the 16-week study duration. On the other hand, OVX-E $E_{2}$ treated rats exhibited modest but significant decreases in BP compared with corresponding SO or OVX rat values (Fig. 2A). More prolonged periods of bradycardia (weeks 4-10; Fig. 2B) were also demonstrated in OVX-E $\mathrm{E}_{2}$ treated rats. Myocardial contractility $\left(+\mathrm{dP} / \mathrm{dt}_{\max }\right)$ showed significant reductions in the two OVX groups prior to estrogen administration (weeks 1-3; Fig. 3). The reduction in $+\mathrm{dP}^{\prime} / \mathrm{dt}_{\max }$ continued in vehicle-treated OVX rats until the end of the study (Fig. 3). Estrogen supplementation in OVX rats restored $+\mathrm{dP} / \mathrm{dt}_{\max }$ to levels that were similar or higher than corresponding $\mathrm{SO}$ values (Fig. 3).

Figures 4-6 illustrate the effects of OVX and estrogen replacement on spectral measures of cardiovascular autonomic control. Compared with SO values, the spectral density of IBI in the $\mathrm{HF}$ range $\left(\mathrm{IBI}-\mathrm{HF}_{\mathrm{nu}}, 0.75-3 \mathrm{~Hz}\right.$ ) was significantly decreased by OVX whereas the LF $\left(\mathrm{IBI}_{-}-\mathrm{LF}_{\mathrm{nu}}, 0.20-0.75 \mathrm{~Hz}\right.$ ) oscillations of IBI were significantly increased (Fig. 4B). Further, the $\mathrm{IBI}_{\mathrm{LF} / \mathrm{HF}}$ ratio, a measure of cardiac sympathovagal balance, showed significant increases in OVX compared with SO values (Fig. 4C). Treatment of OVX rats with estrogen restored spectral densities of IBI spectra to SO levels (Fig. 4). SBP spectra in the LF range were not affected by OVX but showed significant and sustained reductions in OVX- $\mathrm{E}_{2}$ treated rats (Fig. 5). The spectral index of spontaneous baroreflex sensitivity $\mathrm{HFa}$ (Fig. 6A), but not $\mathrm{LFa}$ (Fig. 6B), was reduced in OVX and restored to near-SO values in OVX-E 2 treated rats.

\section{Discussion}

The study of hemodynamic variability is an important measure of the cardiovascular autonomic function. The apparently conflicting reports regarding the effect of hormone replacement therapy on hemodynamic variability $(14,17-19)$ together with the failure of some recent clinical trials to provide evidence of cardioprotection (6) raised some doubts about the safety of hormonal therapy in postmenopausal women. The present study provides longitudinal evaluation of the effect of estrogen supplementation on hemodynamic and autonomic profiles in telemetered female rats. The most important effects of estrogen replacement in OVX rats are: (i) decreases in BP and in LF oscillations of SBP, which may reflect increased vasomotor sympathetic tone, (ii) increases in $+\mathrm{dP} / \mathrm{dt}_{\max }$ of arterial pressure, an estimate of myocardial contractility, (iii) abolition of the detrimental effects of OVX on cardiac sympathovagal balance, and (iv) facilitation of spontaneous baroreflex sensitivity. These findings demonstrate that estrogen replacement virtually abolishes imbalances in the cardiovascular autonomic control induced by hormonal (estrogen) deficiency in OVX rats.

We report no changes in BP during the 16-week post-ovariectomy period, thereby suggesting no role for ovarian hormones in the long-term tonic regulation of BP. The lack of effect for OVX on BP mimics clinical reports, which failed to detect any appreciable BP changes in association with menopausal transition in either African-American or white women (26). In fact, a cross-sectional survey showed that the increase in BP after menopause takes up to 20 years to develop (27), which raises the possibility that other non- 
hormonal factors might also be involved. Experimental reports in female rats have shown that the effect of OVX on BP is influenced by baseline BP. Whereas ovariectomy has no effect on BP in normotensive rats $(20,24)$, it augments the progression of hypertension in Dahl salt-sensitive (28) and spontaneously hypertensive (29) rats. However, in some reports $(30,31)$, an increase in BP has been demonstrated in normotensive rats following OVX. These studies, however, suffered two limitations: (i) hemodynamic measurements were undertaken in anesthetized rats, and (ii) BP was measured only once 6 weeks after OVX $(30,31)$. Notably, anesthesia is known to alter hemodynamic and autonomic control (32). These confounding factors were circumvented in the present study by utilizing the radiotelemetry technique, which allows continuous and uninterrupted accurate measurement of BP in conscious animals for extended period of time in their home cages.

Although depletion of ovarian hormones failed to alter BP, supplementation of OVX rats with estrogen elicited modest but sustained reductions in BP that amounted to 3-6 $\mathrm{mmHg}$. A similar trend was demonstrated in the same rat model (20) and in postmenopausal women (33) receiving estrogen therapy. The reason as to why BP was affected by estrogen repletion but not depletion (OVX) is not clear. It could be argued that the presence of supraphysiological estrogen levels in OVX-E2 rats might have contributed to the reduction in BP. This assumption, however, seems unlikely because a similar fall in BP was demonstrated in the same rat model that exhibited physiological levels of the hormone (20). Alternatively, a role for differences in the characteristics of hormonal milieu is the hypotension caused by estrogen supplementation is possible. Obviously, hormonal depletion produced by ovariectomy involves both estrogen and progesterone. Even when compared to intact female rats, estrogen-treated OVX rats exhibit distinctly different hormonal characteristics both qualitatively (estrogen+progestin vs. estrogen alone) and quantitatively (cyclical vs. fixed levels of estrogen) $(20,34)$. Reported studies showed that the two female steroidal sex hormones may produce opposite vascular effects (35) and the cardiovascular effects of estrogen might be altered when used concurrently with progesterone (36).

In the current study, frequency domain analysis of hemodynamic variability yielded important information that may explain the hypotensive action of estrogen. The significant decrease in oscillations of SBP in the LF range, a measure of vasomotor sympathetic tone $(21,23)$, suggests a possible role for reduced vascular sympathetic activity, and subsequently peripheral vascular resistance, in the BP lowering effect of estrogen. The involvement of the central nervous system in mediating these effects of estrogen is plausible since chronic medullary injections of estrogen in OVX rats have been shown to reduce renal sympathetic activity and BP (37). Saleh et al. (13) implicated the nucleus of the solitary tract and rostral ventrolateral medulla, brainstem areas that control baroreflexes and bulbospinal preganglionic sympathetic discharges (38), in the sympathoinhibitory effect of estrogen. The anatomical localization of estrogen receptors in these brainstem areas (39) further affirms the crucial role of estrogen in central control of cardiovascular autonomic activity. Notably, the reduction in SBP oscillations by estrogen may have important clinical implications because BP variability correlates positively with the severity of end-organ damage (40). Also, long-term reductions in BP variability may promote regression of ventricular and vascular hypertrophy in patients with cardiovascular disease (41).

The radiotelemetry technique allows the computation of the maximum rate of pressure rise across the blood pressure waveform $\left(+\mathrm{dP} / \mathrm{dt}_{\max }\right)$, which serves as an estimate of myocardial contractility $(21,22)$. Our results showed that estrogen replacement abolished the reductions in myocardial contractility observed in OVX rats. Whether this effect of estrogen is directly mediated at the heart level was not investigated in the present study. However, this effect of estrogen may conceivably be accounted for by the ability of estrogen to reduce vascular sympathetic activity, which we demonstrated in the present study (reduced LF oscillations of 
SBP), and subsequent reduction in vascular resistance (cardiac afterload) (42). Alternatively, others suggested a role for facilitation of nitric oxide synthase activity in the estrogenevoked decreases in vascular resistance and subsequent increases in cardiac output and ejection fraction (43). Further studies are needed to investigate the mechanisms implicated in this interesting finding. In addition to the reduction in cardiac afterload, other mechanisms such as antioxidant activity (44), increasing calcium availability (45) have also been implicated in the increased myocardial contractility caused by estrogen.

Menopause is associated with facilitation and attenuation of sympathetic and parasympathetic control of the heart, respectively (14). This pattern of compromised cardiac autonomic activity is normalized after estrogen replacement in some studies $(14,17)$. In other studies, HRV was not affected (18) or, surprisingly, showed more deterioration (19) in response to estrogen. In this study, ovariectomy (model of surgical menopause) had no effect on HR but caused detrimental changes in the variability of HR. OVX caused reciprocal changes in IBI oscillations in the HF (decreases) and LF (increases) power, which reflects reduced and enhanced cardiac vagal and sympathetic activities, respectively. These autonomic changes resulted in a shift in cardiac sympathovagal balance towards sympathetic dominance as suggested by the significant increase in the $\mathrm{IBI}_{\mathrm{LF} / \mathrm{HF}}$ ratio. The adverse HRV effects caused by ovariectomy appear to be causally related to estrogen deficiency because they disappeared after estrogen repletion. The increase in cardiac parasympathetic control in estrogen-treated OVX rats may also explain the bradycardia seen in OVX-E 2 treated rats during the early weeks of the study.

Baroreflex dysfunction is considered an important independent risk factor for cardiac mortality (46). Spectral analysis of the IBI-SBP relationship was used to determine whether changes in arterial baroreceptor activity had contributed to the OVX-evoked alterations in the overall cardiac autonomic control. We show that ovariectomy reduced spontaneous baroreflex activity in the high frequency $\left(\mathrm{HF}_{\mathrm{a}}\right)$ but not low frequency $\left(\mathrm{LF}_{\mathrm{a}}\right)$ spectral bands. Because $\mathrm{HF}_{\mathrm{a}}$ is mainly a measure of cardiomotor vagal activity $(22,23)$, its reduction reflects selective inhibition of the reflex control of cardiac parasympathetic activity in ovariectomized rats. These findings also raise the possibility that ovarian hormones might be acting tonically to facilitate baroreflex responsiveness. Indeed, supplementation of OVX rats with estradiol restored $\mathrm{HF}_{\mathrm{a}}$ to intact (sham-operated) levels. These findings are in agreement with reported studies, which utilized the vasoactive (Oxford) method for evaluating baroreflex activity and found that OVX and estrogen replacement decreases and increases, respectively, reflex bradycardic responses in rats (11-13) and mice (47). The demonstration by Pamidimukkala et al. (47) that estrogen replacement enhances baroreflex gain in the wild-type OVX rats but not in the estrogen receptor-a knockout OVX rats directly implicates estrogen receptor- $a$ in the baroreflex response to estrogen. Notably, the sympathetically-mediated reflex tachycardia tested with sodium nitroprusside was not influenced by hormonal manipulations $(11,12)$. In effect, the first evidence that implicated central projections of arterial baroreceptors in the estrogen-baroreflex interaction was established in our laboratory (12) and then confirmed later by others (13). It is notable that the facilitation of baroreflex activity may also contribute to hypotensive effect of estrogen seen in OVX rats. Several studies have shown that the increase in arterial baroreflex responsiveness allows better control of BP and HR oscillations $(48,49)$ and that arterial baroreceptor denervation results in greater variability in $\mathrm{BP}(50)$.

Despite its importance in defining the autonomic control of the circulation, the use of HRV as a measure of cardiac autonomic activity suffers some limitations. For example, the cardiac parasympathetic control is not the only determinant of the HF oscillations of HRV. The residual HF oscillations seen after autonomic blockade or cardiac transplantation has been attributed to mechanical modulation of sinus node by respiration (51). Also, in addition 
to the sympathetic drive, the parasympathetic control as well as humoral factors, gender, and age contribute to the LF component of HRV (52). Representation of LF and HF powers in normalized units or the computation of the LF/HF power ratio increases the reliability of spectral parameters in reflecting cardiac autonomic modulation $(23,52)$. Both approaches were utilized in the current study. Alternatively, although the BRS estimates provided by spontaneous hemodynamic variability correlate with the vasoactive (Oxford) method, the two techniques may not be quantitatively similar (53).

It is imperative to comment on the plasma level of estrogen achieved in estrogen-replaced OVX rats. As described in previous studies (25), 17ß-estradiol-filled Silastic tubings were employed in the current study for estrogen replacement. With this regimen, the highest level of plasma estrogen was observed after 2 weeks of subcutaneous implantation and then the level declined gradually to approximately steady levels after 8 weeks (i.e. week 11 of the study, see Table 1). Despite the fluctuations in hormonal levels, the early changes in BP, myocardial contractility, and cardiovascular autonomic control caused by estrogen repletion were maintained throughout the 13-week period of the study. More importantly, even with the apparently supra-physiological estrogen levels achieved in OVX-E 2 compared with SO rats, most of the hemodynamic abnormalities evoked by depletion of gonadal hormones in female rats were clearly rectified after estrogen replacement. Notably, plasma estrogen was measured in SO rats irrespective of the stage of the estrus cycle. However, the estrogen levels observed in these rats were comparable to those achieved during the proestrus phase (34).

The main focus of the current study was to evaluate the isolated hemodynamic and autonomic effects of estrogen, considering the importance of estrogen monotherapy in clinical conditions such as osteoporosis (54). Reported findings, however, have shown that the estrogen effects might be altered by progesterone. Indeed, contrasting effects for estrogen and progesterone on reflex autonomic control of the circulation have been demonstrated (11-13,55,56). Further, the use of progestogen-containing replacement therapy in postmenopausal women increases HR, attenuates HRV and abolishes falls in BP elicited by estrogen (19). Little information is available with regard to the effect of progesterone on cardiac contractility. In few studies, progesterone derivatives have been shown to enhance contractility of isolated cardiac muscle $(57,58)$. In addition to the dependence of cardiovascular autonomic control on the type of gonadal hormones (estrogen vs. progesterone), the cyclic variation in hormonal levels is also an important modulator of the autonomic drive. Princi et al. (59) demonstrated higher HR variability and increased and decreased HF and LF oscillations, respectively, during the luteal compared with the follicular phase. Others reported significant correlation between peak estrogen levels and HRV measures at ovulation (60). With that in mind, the utilization of our telemetered rat model to investigate the cardiovascular and autonomic effects of the combined estrogen plus progesterone therapy as well as cyclic variations in hormonal levels is necessary. These issues will be addressed in future studies.

The present observation that body weight was reduced by OVX and restored to shamoperated after estrogen replacement is consistent with previous reports including our own $(24,28)$. Indeed, the estrogen level positively and negatively correlates with energy expenditure and food intake (61). The underlying mechanism may involve the ability of estrogen to increase the satiating potency of cholecystokinin (CCK) released from the small intestine (62). Further, estrogen is believed to promote the effects of the adipocyte-secreted hormone leptin, which decreases feeding and promotes energy expenditure and energyintensive neuroendocrine processes (63). It is imperative to note that estrogen exerts antihypertrophic effects in some organs such as the heart but this effect is unlikely to contribute to the overall reduction in body weight caused by estrogen (64). 
In summary, radiotelemetry was employed in the current study to evaluate the long-term hemodynamic effects of estrogen deficiency and reinstatement in rats. Although BP was not affected by ovariectomy, estrogen replacement reduced BP probably via inhibition of vasomotor sympathetic activity and enhancement of spontaneous BRS. The reduction in vascular resistance (reduced SBS LF spectrum, index of vascular sympathetic tone) may contribute to the increase in $+\mathrm{dP} / \mathrm{dt}_{\max }$ of arterial pressure, an estimate of myocardial contractility. Moreover, estrogen supplementation reversed abnormalities in cardiac autonomic control caused by the deficiency in ovarian hormones. Estrogen facilitated arterial baroreflex activity and shifted cardiac sympathovagal balance towards parasympathetic dominance. These effects of estrogen might contribute to cardioprotective effect of estrogen described in earlier studies (1-3).

\section{Acknowledgments}

Supported by Grant R01 AA014441 from the National Institute on Alcohol Abuse and Alcoholism. The authors thank Ms. Kui Sun for her technical assistance.

\section{References}

1. Wenger NK, Speroff L, Packard B. Cardiovascular health and disease in women. N Engl J Med. 1993; 329:249-256.

2. Stampfer MJ, Colditz GA, Willett WC. Menopause and heart disease: a review. Ann NY Acad Sci. 1989; 592:193-203. [PubMed: 2197944]

3. Stampfer MJ, Colditz GA, Willett WC, Manson JE, Rosner B, Speizer FE, Hennekens CH. Postmenopausal estrogen therapy and cardiovascular disease: ten year follow-up from the nurse's health study. N Engl J Med. 1991; 325:756-762. [PubMed: 1870648]

4. Kushwaha RS, Hazzard WR. Exogenous estrogens attenuate dietary hypercholesterolemia and atherosclerosis. Metabolism. 1981; 30:359-366. [PubMed: 7207207]

5. Tostes RC, Nigro D, Fortes ZB, Carvalho MH. Effects of estrogen on the vascular system. Braz J Med Biol Res. 2003; 2003; 36:1143-1158. [PubMed: 12937779]

6. Enserink M. Women's health. The vanishing promises of hormone replacement. Science. 2002; 297:325-326. [PubMed: 12130763]

7. Anderson GL, Limacher M. Assaf AR; Women's Health Initiative Steering Committee. Effects of conjugated equine estrogen in postmenopausal women with hysterectomy: the Women's Health Initiative randomized controlled trial. JAMA. 2004; 291:1701-1712. [PubMed: 15082697]

8. Utian WH. NIH and WHI: time for a mea culpa and steps beyond. Menopause. 2007; 14:10561059. [PubMed: 17975521]

9. Harman SM, Brinton EA, Clarkson T, Heward CB, Hecht HS, Karas RH, Judelson DR, Naftolin F. Is the WHI relevant to HRT started in the perimenopause? Endocrine. 2004; 24:195-202. [PubMed: 15542885]

10. Grady D, Rubin SM, Petitti DB, Fox CS, Black D, Ettinger B, Ernster VL, Cummings SR. Hormone therapy to prevent disease and prolong life in postmenopausal women. Ann Intern Med. 1992; 117:1016-1037. [PubMed: 1443971]

11. El-Mas MM, Abdel-Rahman AA. Estrogen enhances baroreflex control of heart rate in conscious ovariectomized rats. Can J Physiol Pharmacol. 1998; 76:381-386. [PubMed: 9795746]

12. Mohamed MK, El-Mas MM, Abdel-Rahman AA. Estrogen enhancement of baroreflex sensitivity is centrally mediated. Am J Physiol. 1999; 276:R1030-R1037. (Regulatory Integrative Comp. Physiol. 45). [PubMed: 10198382]

13. Saleh MC, Connell BJ, Saleh TM. Medullary and intrathecal injections of 17beta-estradiol in male rats. Brain Res. 2000; 867:200-209. [PubMed: 10837814]

14. Neves VF, Silva de Sá MF, Gallo L Jr, Catai AM, Martins LE, Crescêncio JC, Perpétuo NM, Silva E. Autonomic modulation of heart rate of young and postmenopausal women undergoing estrogen therapy. Braz J Med Biol Res. 2007; 40:491-499. [PubMed: 17401492] 
15. Huikuri HV, Pikkujamsa SM, Airaksinen J, Ikaheimo MJ, Rantala AO, Kauma H, Lilja M, Kesaniemi A. Sex-related differences in autonomic modulation of heart rate in middle-aged subjects. Circulation. 1996; 94:122-125. [PubMed: 8674168]

16. Brockbank CL, Chatterjee F, Bruce SA, Woledge RC. Heart rate and its variability change after the menopause. Exp Physiol. 2000; 85:327-330. [PubMed: 10825420]

17. Liu CC, Kuo TB, Yang CC. Effects of estrogen on gender-related autonomic differences in humans. Am J Physiol Heart Circ Physiol. 2003; 285:H2188-H2193. [PubMed: 12881217]

18. Niskanen L, Laitinen T, Tuppurainen M, Saarikoski S, Kröger H, Alhava E, Hartikainen J. Does postmenopausal hormone replacement therapy affect cardiac autonomic regulation in osteoporotic women? Menopause. 2002; 9:52-57. [PubMed: 11791086]

19. Christ M, Seyffart K, Tillmann HC, Wehling M. Hormone replacement in postmenopausal women: impact of progestogens on autonomic tone and blood pressure regulation. Menopause. 2002; 9:127-136. [PubMed: 11875332]

20. El-Mas MM, Abdel-Rahman AA. An association between the estrogen-dependent hypotensive effect of ethanol and an elevated brainstem c-jun mRNA in female rats. Brain Res. 2001; 912:7988. [PubMed: 11520495]

21. El-Mas MM, Abdel-Rahman AA. Intermittent clonidine regimen abolishes tolerance to its antihypertensive effect: a spectral study. J Cardiovasc Pharmacol. 2007; 49:174-181. [PubMed: 17414230]

22. El-Mas MM, Abdel-Rahman AA. Role of myocardial contractility and autonomic control in the hypotensive response to a limited access ethanol paradigm in SHRs. Alcohol Clin Exp Res. 2007; 31:1071-1079. [PubMed: 17428291]

23. Heart rate variability: standards of measurement, physiological interpretation and clinical use. Task Force of the European Society of Cardiology and the North American Society of Pacing and Electrophysiology. Circulation. 1996; 93:1043-1065. [PubMed: 8598068]

24. El-Mas MM, Abdel-Rahman AA. Ovariectomy alters the chronic hemodynamic and sympathetic effects of ethanol in radiotelemetered female rats. Clin Exp Hypertens. 2000; 22:109-126. [PubMed: 10685729]

25. McNeill AM, Zhang C, Stanczyk FZ, Duckles SP, Krause DN. Estrogen increases endothelial nitric oxide synthase via estrogen receptors in rat cerebral blood vessels: effect preserved after concurrent treatment with medroxyprogesterone acetate or progesterone. Stroke. 2002; 33:16851691. [PubMed: 12053012]

26. Luoto R, Sharrett AR, Schreiner P, Sorlie PD, Arnett D, Ephross S. Blood pressure and menopausal transition: the Atherosclerosis Risk in Communities study (1987-95). J Hypertens. 2000; 18:27-33. [PubMed: 10678540]

27. Burt VL, Whelton P, Roccella EJ, Brown C, Cutler JA, Higgins M, Horan MJ, Labarthe D. Prevalence of hypertension in the US adult population. Results from the Third National Health and Nutrition Examination Survey, 1988-1991. Hypertension. 1995; 25:305-313. [PubMed: 7875754]

28. Hinojosa-Laborde C, Craig T, Zheng W, Ji H, Haywood JR, Sandberg K. Ovariectomy augments hypertension in aging female Dahl salt-sensitive rats. Hypertension. 2004; 44:405-409. [PubMed: 15337736]

29. Ito K, Hirooka Y, Kimura Y, Sagara Y, Sunagawa K. Ovariectomy augments hypertension through rho-kinase activation in the brain stem in female spontaneously hypertensive rats. Hypertension. 2006; 48:651-657. [PubMed: 16940229]

30. Mercier I, Pham-Dang M, Clement R, Gosselin H, Colombo F, Rouleau JL, Calderone A. Elevated mean arterial pressure in the ovariectomized rat was normalized by ET(A) receptor antagonist therapy: absence of cardiac hypertrophy and fibrosis. Br J Pharmacol. 2002; 136:685-692. [PubMed: 12086977]

31. Thorin E, Pham-Dang M, Clement R, Mercier I, Calderone A. Hyper-reactivity of cerebral arteries from ovariectomized rats: therapeutic benefit of tamoxifen. Br J Pharmacol. 2003; 140:1187-1192. [PubMed: 14597597]

32. El-Mas MM, Tao S, Carroll RG, Abdel-Rahman AA. Ethanol-clonidine hemodynamic interaction in normotensive rats is modified by anesthesia. Alcohol. 1994; 11:307-314. [PubMed: 7945985] 
33. DeMeersman RE, Zion AS, Giardina E, Weir JP, Lieberman JS, Downey JA. Estrogen replacement, vascular distensibility, and blood pressure in postmenopausal women. Am J Physiol. 1998; 274:H1539-1544. [PubMed: 9612361]

34. Marcondes FK, Miguel KJ, Melo LL, Spadari-Bratfisch RC. Estrous cycle influences the response of female rats in the elevated plus-maze test. Physiol Behav. 2001; 74:435-440. [PubMed: 11790402]

35. Szelke E, Varbiro S, Mersich T, Banhidy F, Szekacs B, Sandor P, Komjati K. Effects of estrogen and progestin on hypothalamic blood flow autoregulation. J Soc Gynecol Investig. 2005; 12:604609.

36. Eikelis N, Van Den Buuse M. Cardiovascular responses to open-field stress in rats: sex differences and effects of gonadal hormones. Stress. 2000; 3:319-334. [PubMed: 11342397]

37. Saleh MC, Connell BJ, Saleh TM. Autonomic and cardiovascular reflex responses to central estrogen injection in ovariectomized female rats. Brain Res. 2000; 879:105-114. [PubMed: 11011011]

38. Chalmers J, Pilowsky P. Brainstem and Bulbospinal neurotransmitter systems in the control of blood pressure. J Hypertens. 1991; 9:675-694. [PubMed: 1680911]

39. Haywood SA, Simonian SX, van der Beek EM, Bicknell RJ, Herbison AE. Fluctuating estrogen and progesterone receptor expression in brainstem norepinephrine neurons through the rat estrous cycle. Endocrinology. 1999; 140:3255-3263. [PubMed: 10385422]

40. Mancia G, Parati G. Ambulatory blood pressure monitoring and organ damage. Hypertension. 2000; 36:894-900. [PubMed: 11082163]

41. Strauer BE. Regression of myocardial and coronary vascular hypertrophy in hypertensive heart disease. J Cardiovasc Pharmacol. 1988; 12(Suppl 4):S45-54. [PubMed: 2468873]

42. Moore A, Mangoni AA, Lyons D, Jackson SH. The cardiovascular system. Br J Clin Pharmacol. 2003; 56:254-260. [PubMed: 12919173]

43. Beyer ME, Yu G, Hanke H, Hoffmeister HM. Acute gender-specific hemodynamic and inotropic effects of 17beta-estradiol on rats. Hypertension. 2001; 38:1003-1010. [PubMed: 11711489]

44. Satoh M, Matter CM, Ogita H, Takeshita K, Wang CY, Dorn GW 2nd, Liao JK. Inhibition of apoptosis-regulated signaling kinase- 1 and prevention of congestive heart failure by estrogen. Circulation. 2007; 115:3197-3204. [PubMed: 17562954]

45. Buitrago C, Massheimer V, de Boland AR. Acute modulation of $\mathrm{Ca} 2+$ influx on rat heart by 17beta-estradiol. Cell Signal. 2000; 12:47-52. [PubMed: 10676847]

46. Schwartz PJ, Billman GE, Stone HL. Autonomic mechanisms in ventricular fibrillation induced by myocardial ischemia during exercise in dogs with a healed infarction: an experimental preparation for sudden cardiac death. Circulation. 1984; 69:780-790.

47. Pamidimukkala J, Xue B, Newton LG, Lubahn DB, Hay M. Estrogen receptor-alpha mediates estrogen facilitation of baroreflex heart rate responses in conscious mice. Am J Physiol Heart Circ Physiol. 2005; 288:H1063-1070. [PubMed: 15550515]

48. Elghozi JL, Laude D, Janvier F. Clonidine reduces blood pressure and heart rate oscillations in hypertensive patients. J Cardiovasc Pharmacol. 1991; 17:935-940. [PubMed: 1714018]

49. Su DF, Cerutti C, Barres C, Vincent M, Sassard J. Blood pressure and baroreflex sensitivity in conscious hypertensive rats of Lyon strain. Am J Physiol. 1986; 251:H1111-1117. [PubMed: 3789164]

50. El-Mas MM, Carroll RG, Abdel-Rahman AA. Centrally mediated reduction in cardiac output elicits the enhanced hypotensive effect of clonidine in conscious aortic barodenervated rats. J. Cardiovasc Pharmacol. 1994; 24:184-193. [PubMed: 7526049]

51. Bernardi L, Keller F, Sanders M, Reddy PS, Griffith B, Meno F, Pinsky MR. Respiratory sinus arrhythmia in the denervated human heart. J Appl Physiol. 1989; 67:1447-1455. [PubMed: 2793748]

52. Parati G, Mancia G, Di Rienzo M, Castiglioni P, Taylor JA, Studinger P. Point:Counterpoint: Cardiovascular variability is/is not an index of autonomic control of circulation. J Appl Physiol. 2006; 101:676-682. [PubMed: 16645191]

53. Parati G, Di Rienzo M, Mancia G. How to measure baroreflex sensitivity: from the cardiovascular laboratory to daily life. J Hypertens. 2000; 18:7-19. [PubMed: 10678538] 
54. Suzuki A, Sekiguchi S, Asano S, Itoh M. Pharmacological topics of bone metabolism: recent advances in pharmacological management of osteoporosis. J Pharmacol Sci. 2008; 106:530-535. [PubMed: 18431035]

55. Masilamani S, Heesch CM. Effects of pregnancy and progesterone metabolites on arterial baroreflex in conscious rats. Am J Physiol. 1997; 272:R924-R934. (Regulatory Integrative Comp Physiol 41). [PubMed: 9087656]

56. Charkoudian N. Influences of female reproductive hormones on sympathetic control of the circulation in humans. Clin Auton Res. 2001; 11:295-301. [PubMed: 11758795]

57. Templeton JF, Kumar VP, Bose D, Smyth DD, Kim RS, LaBella FS. Digitalis-like pregnanes. Cardiac and renal effects of a glycoside of 14 beta-hydroxyprogesterone. Can J Physiol Pharmacol. 1988; 66:1420-1424. [PubMed: 3242776]

58. Bose D, Elliott D, Kobayashi T, Templeton JF, Kumar VP, LaBella FS. 14 betaHydroxyprogesterone binds to the digitalis receptor, inhibits the sodium pump and enhances cardiac contractility. Br J Pharmacol. 1988; 93:453-461. [PubMed: 3359115]

59. Princi T, Parco S, Accardo A, Radillo O, De Seta F, Guaschino S. Parametric evaluation of heart rate variability during the menstrual cycle in young women. Biomed Sci Instrum. 2005; 41:340 345. [PubMed: 15850129]

60. Leicht AS, Hirning DA, Allen GD. Heart rate variability and endogenous sex hormones during the menstrual cycle in young women. Exp Physiol. 2003; 88:441-446. [PubMed: 12719769]

61. Mystkowski P, Schwartz MW. Gonadal steroids and energy homeostasis in the leptin era. Nutrition. 2000; 16:937-946. [PubMed: 11054599]

62. Thammacharoen S, Lutz TA, Geary N, Asarian L. Hindbrain administration of estradiol inhibits feeding and activates estrogen receptor-alpha-expressing cells in the nucleus tractus solitarius of ovariectomized rats. Endocrinology. 2008; 149:1609-1617. [PubMed: 18096668]

63. Gao Q, Horvath TL. Cross-talk between estrogen and leptin signaling in the hypothalamus. Am J Physiol Endocrinol Metab. 2008; 294:E817-826. [PubMed: 18334610]

64. Lekgabe ED, Royce SG, Hewitson TD, Tang ML, Zhao C, Moore XL, Tregear GW, Bathgate RA, $\mathrm{Du}$ XJ, Samuel CS. The effects of relaxin and estrogen deficiency on collagen deposition and hypertrophy of nonreproductive organs. Endocrinology. 2006; 147:5575-5583. [PubMed: 16935837] 


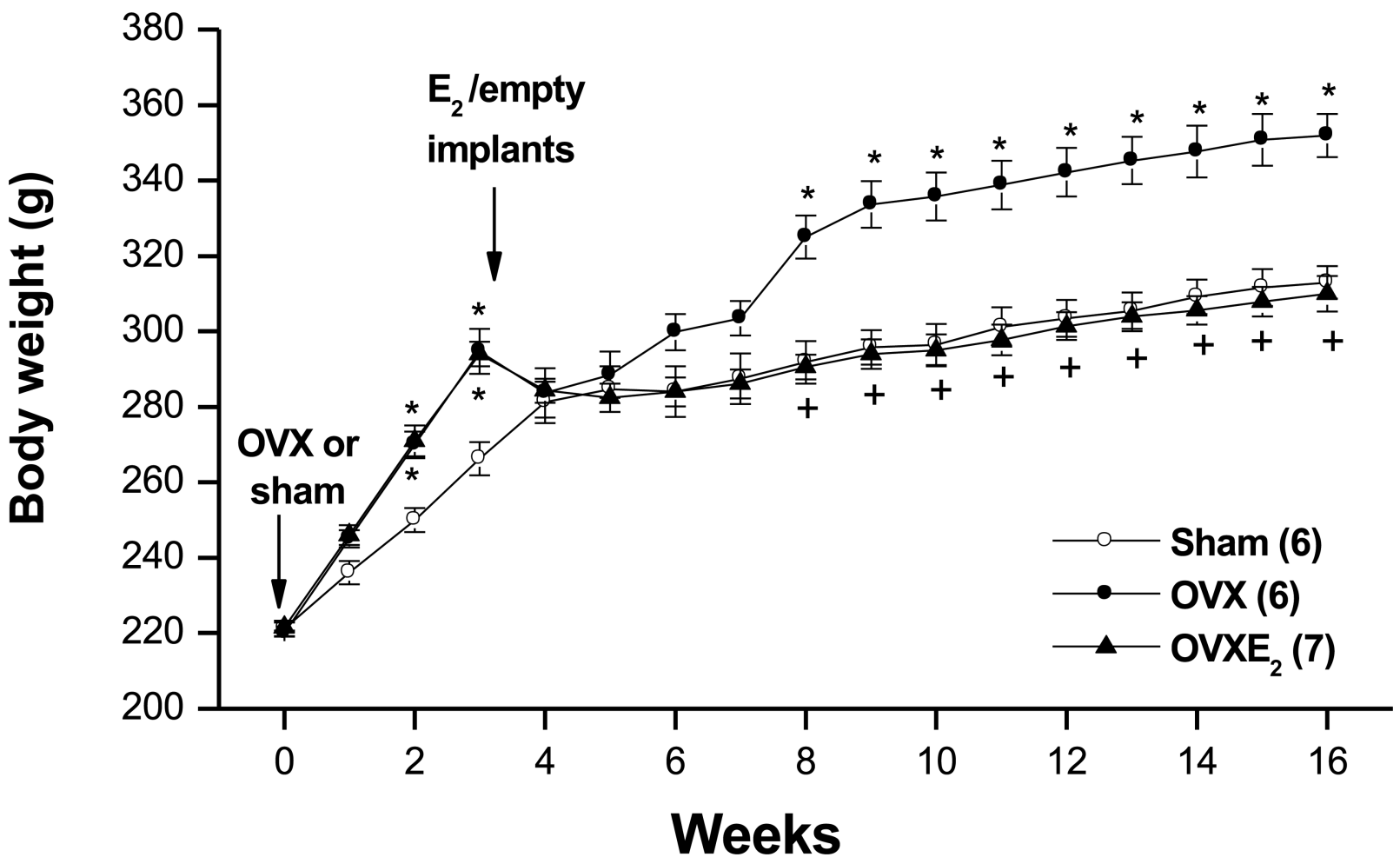

Figure 1.

Body weights of sham-operated, ovariectomized (OVX), or estrogen-replaced OVX $\left(\mathrm{OVXE}_{2}\right)$ rats. OVX or sham operation was performed at week 0. For estrogen replacement, $17 \beta$-estradiol-filled Silastic tubings were implanted subcutaneously in OVX rats at week 3. Sham and OVX rats received empty implants at the same time. Values are means \pm S.E.M. Number of rats in each group is shown in parentheses. $* \mathrm{P}<0.05$ versus corresponding sham values, ${ }^{+} \mathrm{P}<0.05$ versus corresponding $\mathrm{OVX}$ values. 

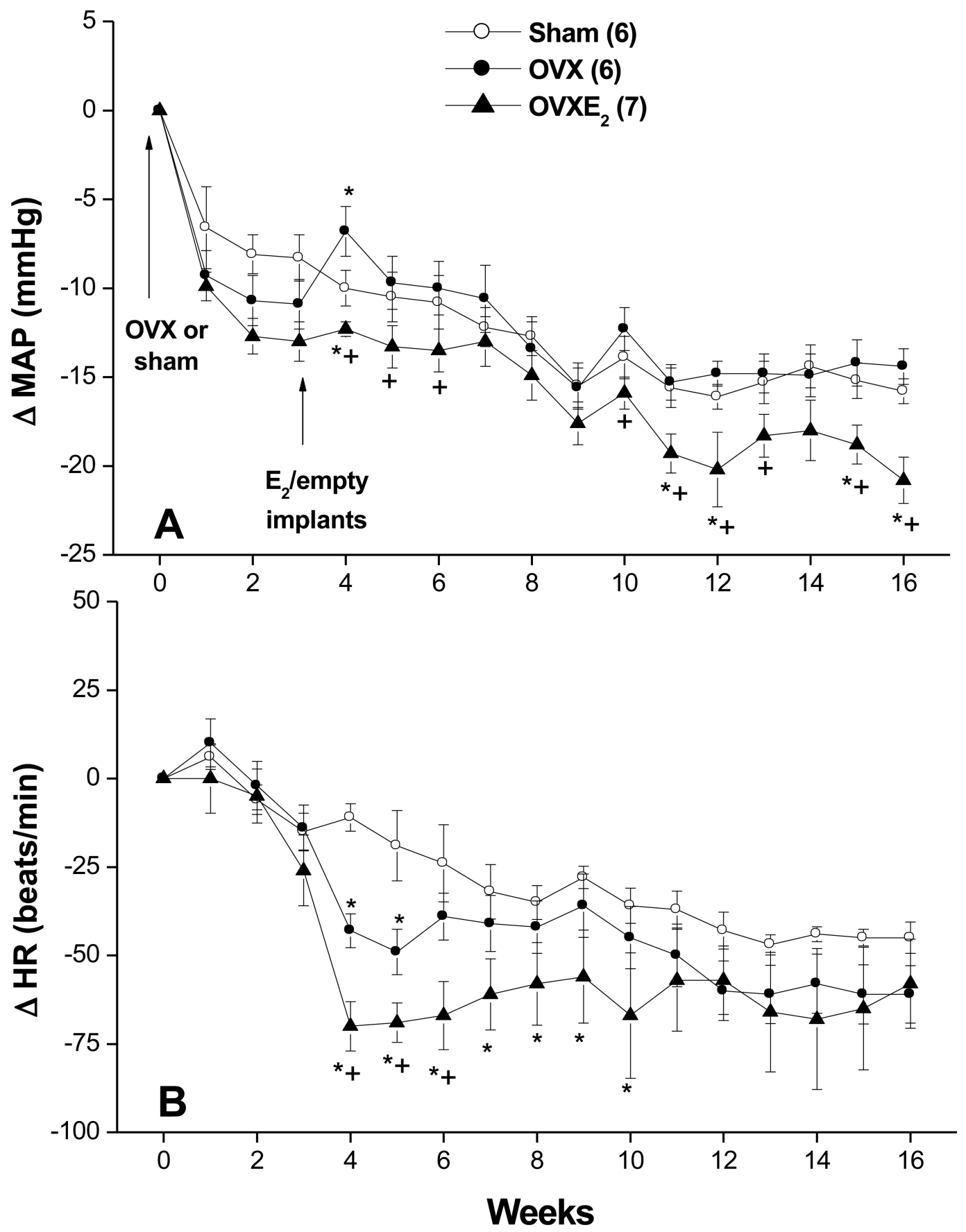

Figure 2.

Changes in mean arterial pressure (MAP, panel A) and heart rate (HR, panel B) in telemetered sham-operated, ovariectomized $(\mathrm{OVX})$, or estrogen-replaced $\mathrm{OVX}\left(\mathrm{OVXE}_{2}\right)$ rats. OVX or sham operation was performed at week 0 . For estrogen replacement, 17 $\beta$ estradiol-filled Silastic tubings were implanted subcutaneously in OVX rats at week 3. Sham and OVX rats received empty implants at the same time. Values are means \pm S.E.M. Number of rats in each group is shown in parentheses. $* \mathrm{P}<0.05$ versus corresponding sham values, ${ }^{+} \mathrm{P}<0.05$ versus corresponding $\mathrm{OVX}$ values. 


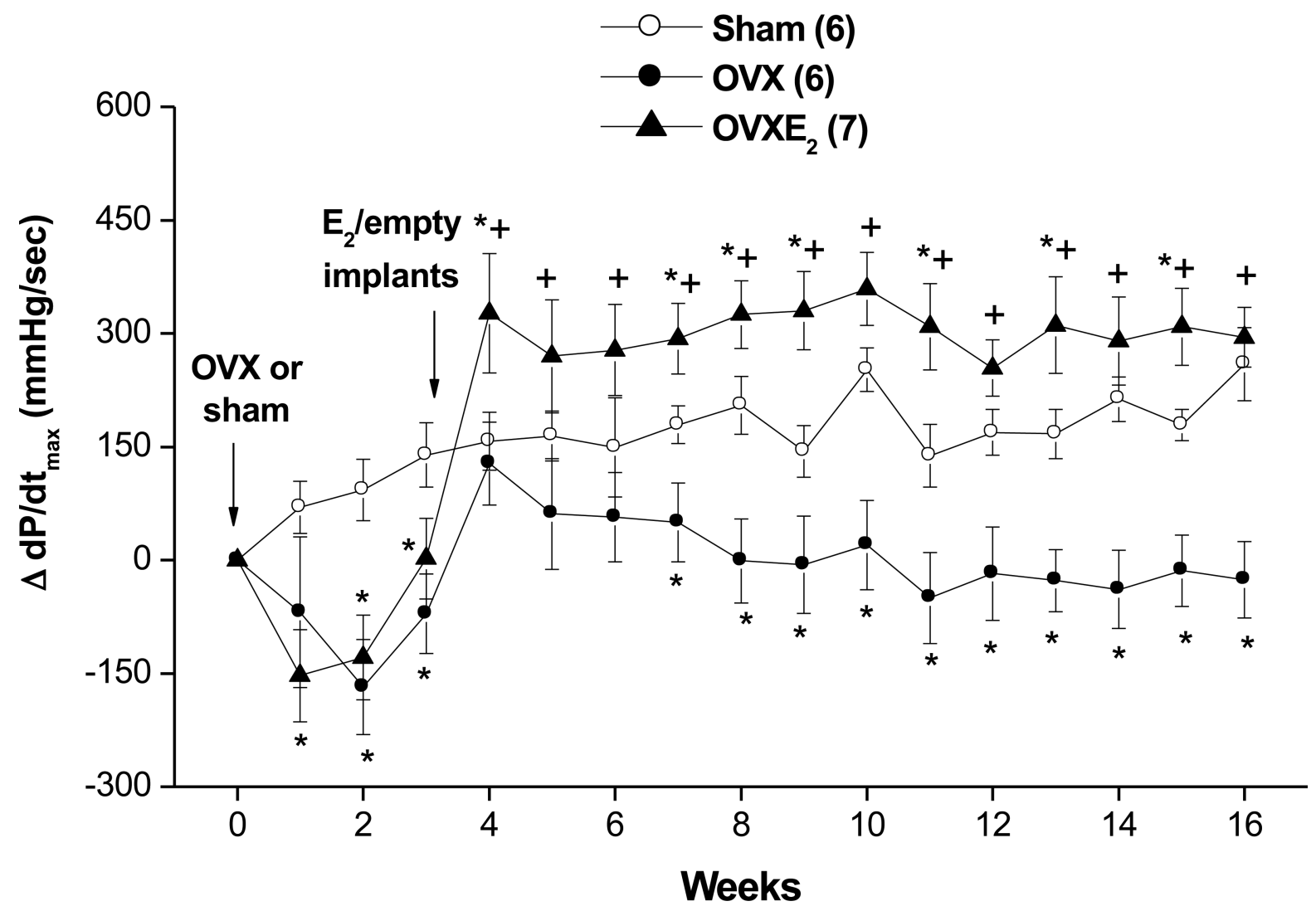

Figure 3.

Changes in myocardial contractility, reflected by the maximum rate of rise of the blood pressure wave $\left(\mathrm{dP} / \mathrm{dt}_{\max }\right)$, in telemetered sham-operated, ovariectomized (OVX), or estrogen-replaced OVX $\left(\mathrm{OVXE}_{2}\right)$ rats. OVX or sham operation was performed at week 0. For estrogen replacement, $17 \beta$-estradiol-filled Silastic tubings were implanted subcutaneously in OVX rats at week 3 . Sham and OVX rats received empty implants at the same time. Values are means \pm S.E.M. Number of rats in each group is shown in parentheses. $* \mathrm{P}<0.05$ versus corresponding sham values, ${ }^{+} \mathrm{P}<0.05$ versus corresponding $\mathrm{OVX}$ values. 

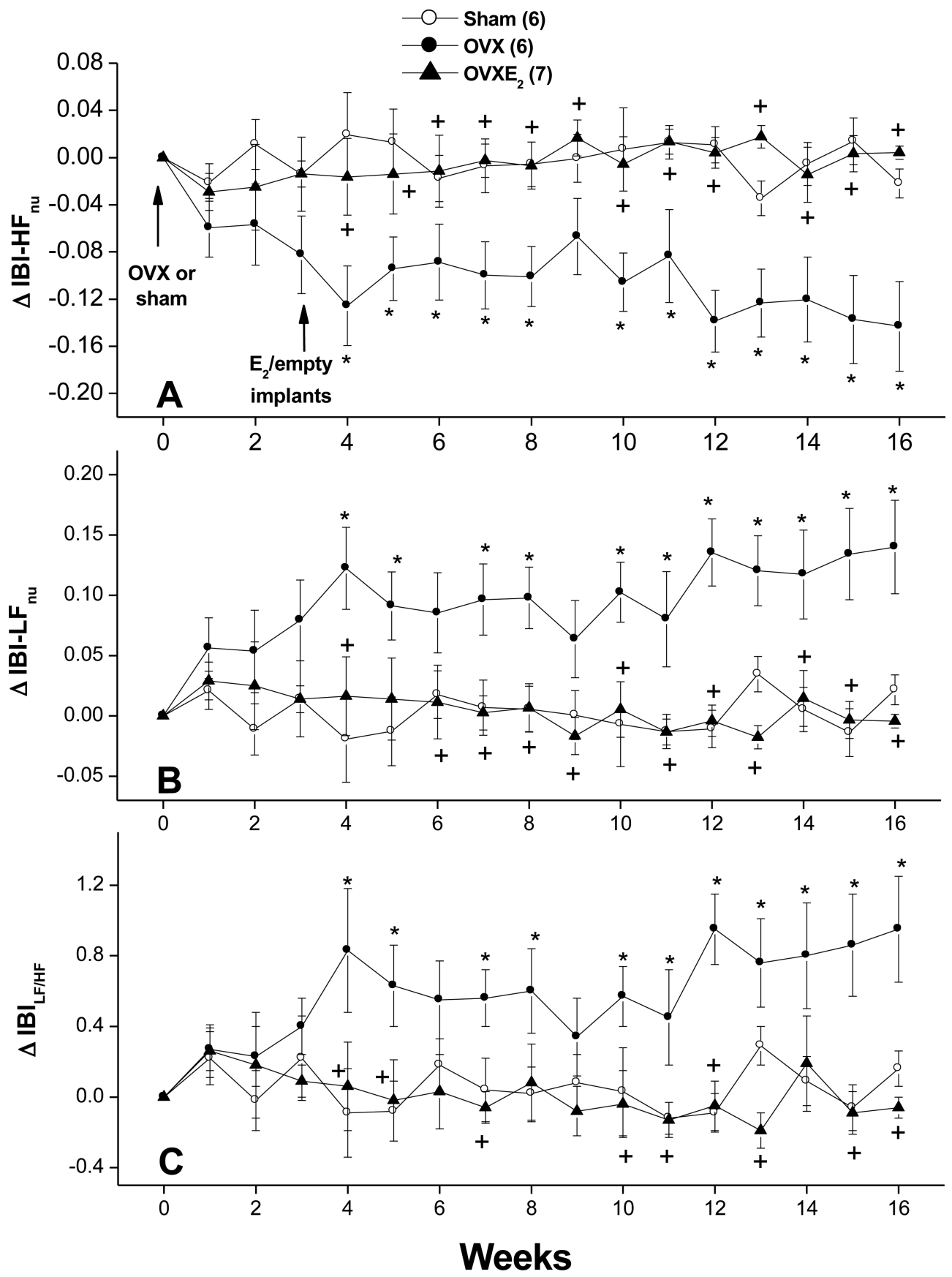

Figure 4.

Changes in spectral densities of interbeat intervals (IBI) in the high-frequency (IBI- $\mathrm{HF}_{\mathrm{nu}}$, $0.75-3 \mathrm{~Hz}$; panel A) and low-frequency (IBI-LF ${ }_{n u}, 0.25-0.75 \mathrm{~Hz}$, panel B) ranges as well as in the $\mathrm{LF} / \mathrm{HF}$ ratio of $\mathrm{IBI}\left(\mathrm{IBI}_{\mathrm{LF} / \mathrm{HF}}\right.$, panel $\left.\mathrm{C}\right)$ in telemetered sham-operated, ovariectomized $(\mathrm{OVX})$, or estrogen-replaced OVX $\left(\mathrm{OVXE}_{2}\right)$ rats. OVX or sham operation was performed at week 0 . For estrogen replacement, $17 \beta$-estradiol-filled Silastic tubings were implanted subcutaneously in OVX rats at week 3 . Sham and OVX rats received empty implants at the same time. Values are means \pm S.E.M. Number of rats in each group is shown in parentheses. $* \mathrm{P}<0.05$ versus corresponding sham values, ${ }^{+} \mathrm{P}<0.05$ versus corresponding $\mathrm{OVX}$ values. 


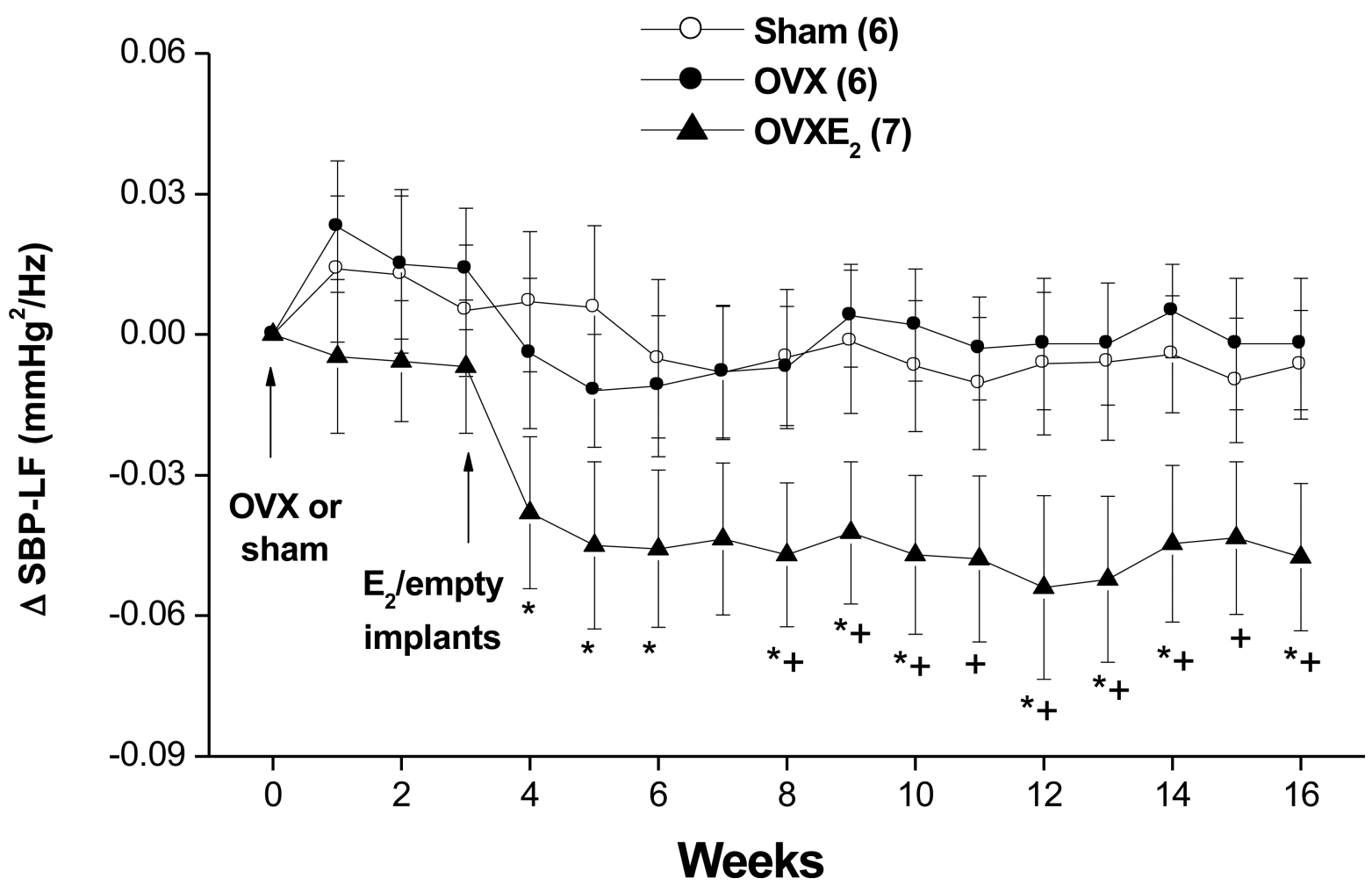

Figure 5.

Changes in spectral density of systolic blood pressure (SBP) in the low-frequency (SBP-LF, $0.25-0.75 \mathrm{~Hz}$, panel B) range in telemetered sham-operated, ovariectomized (OVX), or estrogen-replaced OVX $\left(\mathrm{OVXE}_{2}\right)$ rats. OVX or sham operation was performed at week 0 . For estrogen replacement, $17 \beta$-estradiol-filled Silastic tubings were implanted subcutaneously in OVX rats at week 3 . Sham and OVX rats received empty implants at the same time. Values are means \pm S.E.M. Number of rats in each group is shown in parentheses. ${ }^{*} \mathrm{P}<0.05$ versus corresponding sham values, ${ }^{+} \mathrm{P}<0.05$ versus corresponding $\mathrm{OVX}$ values. 

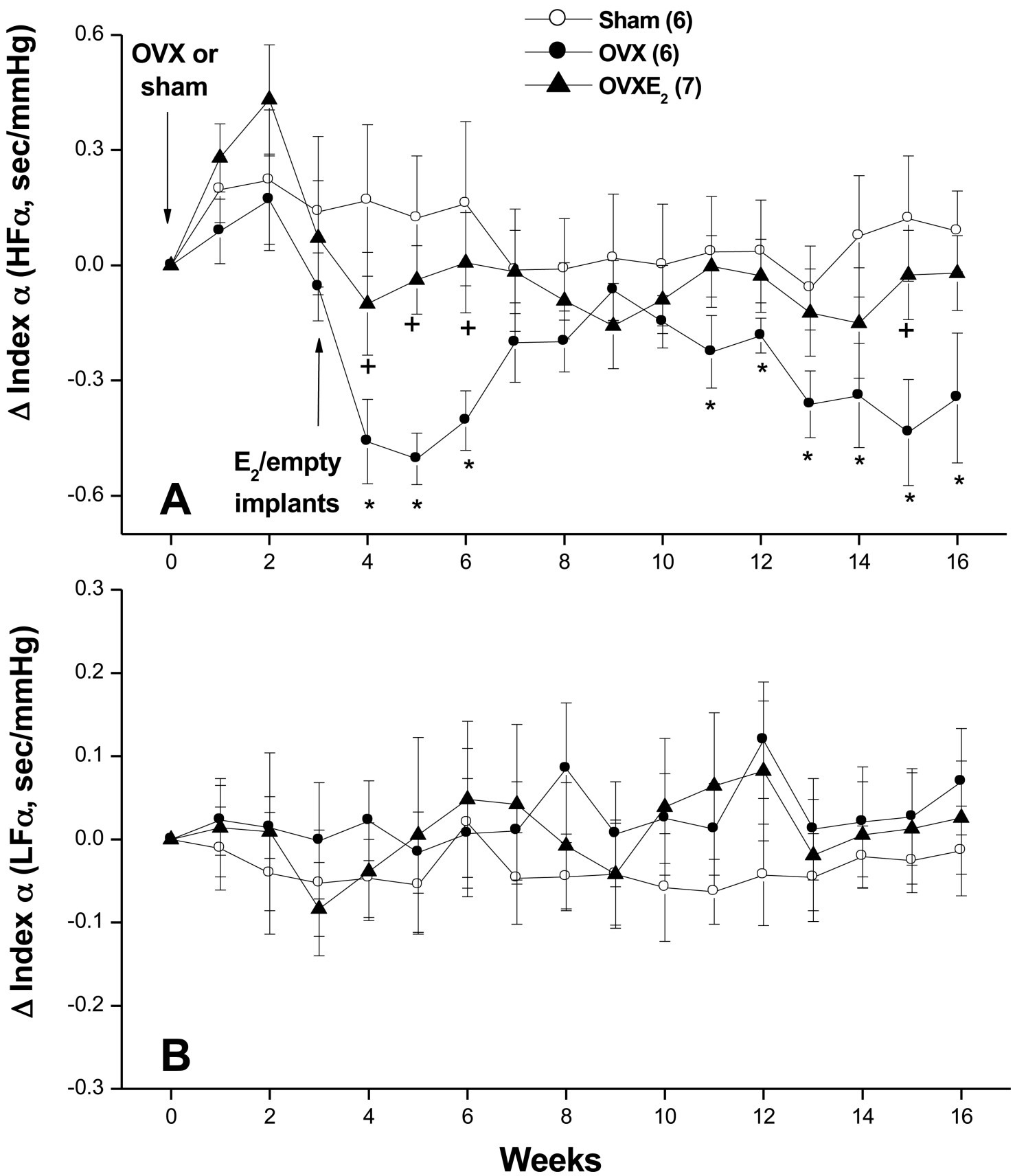

Figure 6.

Changes in index $a$, the spectral index of spontaneous baroreflex gain, in the high-frequency (HF, panel A) and low-frequency (LF, panel B) in telemetered sham-operated, ovariectomized (OVX), or estrogen-replaced OVX $\left(\mathrm{OVXE}_{2}\right)$ rats. OVX or sham operation was performed at week 0 . For estrogen replacement, 17 $\beta$-estradiol-filled Silastic tubings were implanted subcutaneously in OVX rats at week 3 . Sham and OVX rats received empty implants at the same time. Values are means \pm S.E.M. Number of rats in each group is shown in parentheses. ${ }^{*} \mathrm{P}<0.05$ versus corresponding sham values, ${ }^{+} \mathrm{P}<0.05$ versus corresponding OVX values. 


\section{Table 1}

Plasma estradiol levels (pg/ml).

\begin{tabular}{cccc}
\hline Weeks & Sham & OVX & OVXE $_{2}$ \\
\hline Week 0 & $22.5 \pm 0.8$ & $19.4 \pm 3.8$ & $28.2 \pm 2.1$ \\
Week 5 & $22.3 \pm 6.6$ & $4.4 \pm 2.4^{*}$ & $253.1 \pm 24.4^{{ }^{*}+}$ \\
Week 7 & $23.0 \pm 2.1$ & $3.3 \pm 1.1^{*}$ & $107.4 \pm 28.1^{{ }^{*}+}$ \\
Week 9 & $22.3 \pm 1.7$ & $2.3 \pm 0.8^{*}$ & $123.7 \pm 20.6^{{ }^{*}+}$ \\
Week 11 & $21.0 \pm 1.6$ & $4.8 \pm 1.2^{*}$ & $83.7 \pm 11.8^{*+}$ \\
Week 13 & $22.9 \pm 1.8$ & $4.5 \pm 0.7^{*}$ & $76.1 \pm 9.6^{{ }^{*}+}$ \\
Week 16 & $20.4 \pm 2.6$ & $3.8 \pm 0.3{ }^{*}$ & $59.1 \pm 6.3^{*+}$ \\
\hline
\end{tabular}

Values are means \pm S.E.M. of 6-7 observations. For estrogen replacement, $17 \beta$-estradiol-filled Silastic tubings were implanted subcutaneously in OVX rats at week 3 . Sham and OVX rats received empty implants at the same time.

${ }^{*}<0.05$ vs. respective sham values

${ }_{P}^{+}<0.05$ vs. respective OVX values 


\section{Table 2}

Average baseline levels of mean arterial pressure (MAP), heart rate (HR), myocardial contractility $\left(\mathrm{dP} / \mathrm{dt}_{\mathrm{max}}\right)$, spontaneous baroreflex sensitivity (Index a), and spectral powers of hemodynamic variability at low $(0.25-0.75 \mathrm{~Hz})$ and high $(0.75-3 \mathrm{~Hz})$ frequency ranges.

\begin{tabular}{|c|c|c|c|}
\hline Parameter & Sham & OVX & $\mathrm{OVXE}_{2}$ \\
\hline MAP (mmHg) & $118.8 \pm 1.5$ & $116.5 \pm 1.6$ & $118.5 \pm 1.6$ \\
\hline HR (beats/min) & $411.0 \pm 7.8$ & $413.1 \pm 6.9$ & $416.6 \pm 6.9$ \\
\hline $\mathrm{dP} / \mathrm{dt}_{\max }(\mathrm{mmHg} / \mathrm{sec})$ & $1478 \pm 91$ & $1493 \pm 121$ & $1487 \pm 68$ \\
\hline IBI-HF $F_{n u}$ & $0.35 \pm 0.03$ & $0.45 \pm 0.05$ & $0.35 \pm 0.04$ \\
\hline IBI-LF & $0.65 \pm 0.03$ & $0.54 \pm 0.04$ & $0.650 \pm 0.04$ \\
\hline $\mathrm{IBI}_{\mathrm{LF} / \mathrm{HF}}$ & $1.97 \pm 0.19$ & $1.45 \pm 0.38$ & $2.01 \pm 0.24$ \\
\hline SBP-LF (mmHg $\left.{ }^{2} / \mathrm{Hz}\right)$ & $0.151 \pm 0.020$ & $0.180 \pm 0.006$ & $0.162 \pm 0.021$ \\
\hline Index a (HF, sec/mmHg) & $1.56 \pm 0.14$ & $2.16 \pm 0.20$ & $1.50 \pm 0.17$ \\
\hline Index a (LF, sec/mmHg) & $0.82 \pm 0.04$ & $0.73 \pm 0.05$ & $0.78 \pm 0.06$ \\
\hline
\end{tabular}

Values are means \pm SEM of 6-7 observations. MAP, mean arterial pressure; HR, heart rate; IBI, interbeat interval; SBP, systolic blood pressure 